\title{
Studies of Osmotic Diarrhea Induced in Normal Subjects by Ingestion of Polyethylene Glycol and Lactulose
}

\author{
Heinz F. Hammer, Carol A. Santa Ana, Lawrence R. Schiller, and John S. Fordtran \\ Department of Internal Medicine, Baylor University Medical Center, Dallas, Texas 75246
}

\section{Abstract}

The purpose of these studies was to gain insight into the pathophysiology of pure osmotic diarrhea and the osmotic diarrhea caused by carbohydrate malabsorption. Diarrhea was induced in normal volunteers by ingestion of polyethylene glycol (PEG), which is nonabsorbable, not metabolized by colonic bacteria, and carries no electrical charge. In PEG-induced diarrhea, (a) stool weight was directly correlated with the total mass of PEG ingested; (b) PEG contributed 40-60\% of the osmolality of the fecal fluid, the remainder being contributed by other solutes either of dietary, endogenous, or bacterial origin; and (c) fecal sodium, potassium, and chloride were avidly conserved by the intestine, in spite of stool water losses exceeding 1,200 $\mathrm{g} / \mathrm{d}$. Diarrhea was also induced in normal subjects by ingestion of lactulose, a disaccharide that is not absorbed by the small intestine but is metabolized by colonic bacteria. In lactulose-induced diarrhea, $(a)$ a maximum of $\sim 80 \mathrm{~g} / \mathrm{d}$ of lactulose was metabolized by colonic bacteria to noncarbohydrate moieties such as organic acids; (b) the organic acids were partially absorbed in the colon; $(c)$ unabsorbed organic acids obligated the accumulation of inorganic cations ( $\mathrm{Na}>\mathrm{Ca}>\mathrm{K}>\mathrm{Mg}$ ) in the diarrheal fluid; (d) diarrhea associated with low doses of lactulose was mainly due to unabsorbed organic acids and associated cations, whereas with larger doses of lactulose unmetabolized carbohydrates also played a major role; and $(e)$ the net effect of bacterial metabolism of lactulose and partial absorption of organic acids on stool water output was dose dependent. With low or moderate doses of lactulose, stool water losses were reduced by as much as $600 \mathrm{~g} / \mathrm{d}$ (compared with equimolar osmotic loads of PEG); with large doses, the increment in osmotically active solutes within the lumen exceeded the increment of the ingested osmotic load, and the severity of diarrhea was augmented.

\section{Introduction}

Osmotic diarrhea is commonly encountered in clinical practice. Some examples include purposely induced diarrhea with sorbitol to treat hyperkalemia (1), lactulose therapy for hepatic encephalopathy (2), carbohydrate malabsorption due to various intestinal disorders, ingestion of poorly absorbed carbo-

Address correspondence to Dr. John S. Fordtran, Department of Internal Medicine, Baylor University Medical Center, 3500 Gaston Avenue, Dallas, TX 75246.

Received for publication 23 March 1989 and in revised form 21 June 1989.

J. Clin. Invest.

(c) The American Society for Clinical Investigation, Inc. 0021-9738/89/10/1056/07 \$2.00

Volume 84, October 1989, 1056-1062 hydrates occurring naturally in food $(3,4)$ or that are added as sugar substitutes to food (5-7), and gastrointestinal lavage to cleanse the intestine before diagnostic procedures (8). In spite of the frequency and importance of osmotic diarrhea, its pathophysiology has not been carefully studied.

There were two major purposes of our present research. The first was to measure the effect of increasing loads of an osmotic agent on stool water, stool electrolyte composition, and stool concentration of the osmotic agent. Polyethylene glycol 3350 (PEG) $^{1}$ was the osmotic solute for these studies because its absorption is negligible (9), it is not digested by human or bacterial enzymes, and it carries no electrical charge that can influence the movement of other charged solutes. Results with PEG can therefore be used to characterize pure osmotic diarrhea.

The second major purpose was to see to what extent metabolism of the osmotic agent by colonic bacteria would influence stool water and stool electrolyte composition in diarrhea caused by carbohydrate malabsorption. Previous work by others has indicated that such metabolism would mitigate the severity of diarrhea $(10,11)$; however, the degree of stool water reduction and possible effects on stool electrolyte losses have not been quantitated. Lactulose was selected as the osmotic agent for this experiment because it is a disaccharide that is not absorbed by the small intestine (12) but is readily metabolized by colonic bacteria (13); by comparing results in lactulose and PEG-induced diarrhea the effects of metabolism of carbohydrates by bacteria could be assessed.

\section{Methods}

Experimental diarrhea. Normal men, most of them seminary students, ranging in ages from 21 to $32 \mathrm{yr}$, volunteered for these experiments. These studies were approved by the Institutional Review Board for Human Protection of Baylor University Medical Center.

While subjects continued to eat their normal diet, diarrhea was induced by ingestion of a solution containing either $105 \mathrm{~g} /$ liter PEG 3350 or 50 or $70 \mathrm{~g} /$ liter lactulose. $48 \mathrm{mmol} /$ liter $\mathrm{NaCl}, 5 \mathrm{mmol} / \mathrm{liter}$ $\mathrm{KCl}$, and $17 \mathrm{mmol} /$ liter $\mathrm{NaHCO}_{3}$ were added to ensure against the development of electrolyte deficiency due to fecal losses. The osmolality of the PEG solution was $290 \mathrm{mosmol} / \mathrm{kg}$, and of the lactulose solutions 293 and $355 \mathrm{mosmol} / \mathrm{kg}$, respectively. These osmolalities are well within the range of osmolalities of beverages and fluids that people consume normally (14). On four consecutive days the subjects drank $125-600 \mathrm{ml}$ of one of the solutions with each of three meals and with a bedtime snack. During the 4-d period of induced diarrhea, the number of bowel movements/day and dietary intake were recorded on diary sheets. Diary analysis indicated that daily food intake consisted of $104 \pm 6 \mathrm{~g}$ protein, $274 \pm 14 \mathrm{~g}$ carbohydrate, $4.5 \pm 0.4 \mathrm{~g}$ fiber, and $111 \pm 6 \mathrm{~g}$ fat, for a total of $2,527 \pm 94 \mathrm{kcal} / \mathrm{d}$. Subjects were weighed and serum electrolytes, creatinine, and urea nitrogen were determined at the start and end of the experiment; there were no significant changes.

1. Abbreviations used in this paper: PEG, polyethylene glycol. 
Stools were collected quantitatively using preweighed containers during a control period and during ingestion of the osmotically active solute. The stools were kept cooled in an ice chest; unlike a previous study from our laboratory (15) no antibiotics or preservatives were added to stool so as not to change electrolyte concentrations, osmolality, or $\mathrm{pH}$. During the control period stools were returned to the laboratory after completing a 72-h collection, whereas during ingestion of the solute stools were returned after each of four 24-h periods. Since fecal composition during the first day of solute ingestion might have been influenced by residual colonic content before initiation of osmotic diarrhea, only stools from the last $3 \mathrm{~d}$ of the experiment were analyzed.

PEG 3350 was obtained from J. T. Baker Chemical Co., (Phillipsburg, NJ) and lactulose from Fluka Chemie AG (Buchs, Switzerland).

Analytical methods. Electrolyte concentrations, pH, fat, and PEG were determined by methods previously described in our laboratory (16-18). Osmolality was measured by vapor pressure osmometer. Ammonium concentration was measured by the method of Chaney and Marbach (19). Fecal dry weight was measured by freeze drying, and percent water content was calculated as shown in Table $I$.

For determination of organic acid and carbohydrate concentration, stool was ultracentrifuged at $35,000 \mathrm{rpm}$ for $45 \mathrm{~min}$. Water was added to nonwatery stools before ultracentrifugation. Preliminary studies showed that dilution of stool by adding water does not interfere with carbohydrate or organic acid determination when the dilution factor is considered. Supernatant was ultrafiltered using $0.45-\mu \mathrm{m}$ filters (Acrodisc; Gelman Sciences, Inc., Ann Arbor, MI). The total concentration of organic acids (acetic, propionic, butyric, and lactic) was determined by a titration method (20). The validity of this assay was verified in our laboratory. Recovery experiments were performed by adding various amounts of sodium acetate (Mallinckrodt, Inc., St. Louis, MO) to centrifuged stool samples. The recovery was $99 \%$. The interassay coefficient of variation was $1.4 \%$.

Fecal carbohydrates were analyzed by a modification of a spectrophotometric method (21). Carbohydrates, whether they are present as monosaccharides, disaccharides, or oligosaccharides, react with anthrone to produce a green-blue color. Preliminary studies in our laboratory confirmed that there is a linear relationship between carbohydrate concentration and absorbance at $625 \mathrm{~nm}$ over a range of $0-10$ $\mathrm{mg} / 100 \mathrm{ml}$. Compared with glucose as $100 \%$, the absorbance was $96 \%$ for fructose, $81 \%$ for galactose, $80 \%$ for lactose, $80 \%$ for lactulose, $105 \%$ for maltose, $109 \%$ for sucrose, $125 \%$ for D-xylose, $0 \%$ for sorbitol, and $0 \%$ for mannitol. There was no influence of PEG 3350, acetate, butyrate, propionate, or glycine on the absorbance at $625 \mathrm{~nm}$. The color of the anthrone solution with all carbohydrates tested was proven to remain stable over a period of at least $60 \mathrm{~min}$. Glucose standards (2 and $6 \mathrm{mg} / 100 \mathrm{ml}$ ) and a blank (water added to anthrone reagent) were included in each set of determinations. To account for the absorbance due to stool color a second blank, adding diluted supernatant to concentrated sulfuric acid (AR select; Mallinckrodt, Inc.), was included when stool dilutions were 1:700 or less. The absorbance of this blank was read against water at $625 \mathrm{~nm}$ and subtracted from the absorbance of the stool-anthrone sample. Recovery experiments were performed by adding various amounts of glucose to centrifuged stool samples with known carbohydrate concentration. The recovery of glucose was $95 \pm 2 \%$ over a tested range of $300 \mathrm{mg} / \mathrm{liter}-167 \mathrm{~g} /$ liter. The interassay coefficient of variation was $6 \%$.

Calculation of the osmotic load of PEG. Because the osmolality of PEG in solution is not linear with respect to concentration, the osmolality due to PEG in 24-h samples of PEG-induced diarrhea was calculated as the difference in osmolality before and after adding appropriate amounts of PEG to sodium chloride solutions whose concentrations were equal to the sum of the mean concentrations of fecal cations and anions in PEG-induced diarrhea (22). The total osmotic load of PEG in PEG-induced diarrhea was calculated by multiplying the osmolality due to PEG by stool weight.

\section{Results}

Weight and water content of normal stools. Normal stool weight in 72-h pooled stool collections in 13 male subjects was $146 \pm 12 \mathrm{~g} / \mathrm{d}$ (95\% confidence interval, 60-232 g/d). Water content averaged $75 \pm 1 \%$ (95\% confidence interval, 69-82\%). Mean stool frequency was $0.9 \pm 0.1$ bowel movements/day (95\% confidence interval, 0.3-1.5). Stools were formed in all but one subject, who had semiformed bowel movements (stool weight in this subject was $235 \mathrm{~g} / \mathrm{d}$, water content was $81.2 \%$, stool frequency was 1.3 bowel movements/d). These stools were not subjected to further analysis.

Diarrhea induced by PEG. As shown in Table I, stool weight increased from 364 to $1,539 \mathrm{~g} / \mathrm{d}$ when $53-252 \mathrm{~g}$ of PEG was ingested per day. The average weight of individual bowel movements was similar with the three lower PEG doses, but was significantly higher with the highest PEG dose as com-

Table I. Stool Weight, Water Content, Frequency, and Fecal Concentration of PEG, Organic Acids, and Carbohydrates in 24-h Stool Collections (Mean \pm SEM)

\begin{tabular}{|c|c|c|c|c|c|c|c|}
\hline & \multicolumn{4}{|c|}{ PEG } & \multicolumn{3}{|c|}{ Lactulose } \\
\hline & $\begin{array}{c}53 \mathrm{~g} / \mathrm{d} \\
(n=9)\end{array}$ & $\begin{array}{c}95 \mathrm{~g} / \mathrm{d} \\
(n=9)\end{array}$ & $\begin{array}{c}190 \mathrm{~g} / \mathrm{d} \\
(n=12)\end{array}$ & $\begin{array}{l}252 \mathrm{~g} / \mathrm{d} \\
(n=9)\end{array}$ & $\begin{array}{l}45 \mathrm{~g} / \mathrm{d} \\
(n=9)\end{array}$ & $\begin{array}{l}95 \mathrm{~g} / \mathrm{d} \\
(n=9)\end{array}$ & $\begin{array}{l}125 \mathrm{~g} / \mathrm{d} \\
(n=9)\end{array}$ \\
\hline Stool weight $(g / d)$ & $364 \pm 41$ & $589 \pm 45$ & $1,118 \pm 102$ & $1,539 \pm 77$ & $254 \pm 45$ & $550 \pm 115$ & $1,307 \pm 111$ \\
\hline Stool frequency $($ times $/ d)$ & $2 \pm 0.2$ & $3 \pm 0.3$ & $6 \pm 0.3$ & $5 \pm 0.7$ & $2 \pm 0.2$ & $3 \pm 0.3$ & $4 \pm 0.6$ \\
\hline Average weight of individual bowel movement $(g)$ & $226 \pm 34$ & $180 \pm 19$ & $214 \pm 20$ & $398 \pm 64^{*}$ & $149 \pm 23$ & $175 \pm 31$ & $321 \pm 36^{\ddagger}$ \\
\hline Percent water content & $75 \pm 0.4$ & $77 \pm 0.6$ & $79 \pm 0.5$ & $80 \pm 0.4$ & $79 \pm 1$ & $86 \pm 1$ & $90 \pm 0.5$ \\
\hline Stool water output $(g / d)$ & $272 \pm 31$ & $451 \pm 33$ & $881 \pm 58$ & $1,233 \pm 64$ & $202 \pm 38$ & $483 \pm 105$ & $1,184 \pm 106$ \\
\hline PEG (g/liter) & $130 \pm 3$ & $158 \pm 7$ & $165 \pm 2$ & $163 \pm 3^{\ddagger}$ & - & - & - \\
\hline Organic acids (meq/liter) & $81 \pm 7^{\prime \prime}$ & $60 \pm 8$ & $53 \pm 8$ & $31 \pm 3^{*}$ & $231 \pm 23$ & $201 \pm 19$ & $114 \pm 10^{\ddagger}$ \\
\hline Carbohydrate (g/liter) & $0.8 \pm 0.2^{\prime \prime}$ & $1.3 \pm 0.2$ & $0.7 \pm 0.1$ & $0.9 \pm 0.4^{\S}$ & $3.6 \pm 1.3$ & $17 \pm 4$ & $36 \pm 3^{*}$ \\
\hline
\end{tabular}

$n$, Three consecutive 24-h samples from each of three or four subjects. Average weight of individual bowel movements was calculated by dividing daily stool weight by stool frequency. Percent water content was calculated by following formula: $\frac{\text { (original weight) - (dry weight) }}{\text { original weight }}$ $P$ values, unpaired $t$ test $\left(252 \mathrm{~g} / \mathrm{d}\right.$ PEG vs. $53 \mathrm{~g} / \mathrm{d}$ PEG or $125 \mathrm{~g} / \mathrm{d}$ lactulose vs. $95 \mathrm{~g} / \mathrm{d}$ lactulose): ${ }^{*} P<0.01 ;{ }^{\ddagger} P<0.001$. ${ }^{8}$ Not significant. " $n=7$. 
Table II. Electrolyte Concentrations in 24-h Stool Collections (Mean \pm SEM)

\begin{tabular}{|c|c|c|c|c|c|c|}
\hline & \multicolumn{4}{|c|}{ PEG } & \multicolumn{2}{|c|}{ Lactulose } \\
\hline & $\begin{array}{c}53 \mathrm{~g} / \mathrm{d} \\
(n=9)\end{array}$ & $\begin{array}{l}95 \mathrm{~g} / \mathrm{d} \\
(n=9)\end{array}$ & $\begin{array}{c}190 \mathrm{~g} / \mathrm{d} \\
(n=12)\end{array}$ & $\begin{array}{l}252 \mathrm{~g} / \mathrm{d} \\
(n=9)\end{array}$ & $\begin{array}{c}95 \mathrm{~g} / \mathrm{d} \\
(n=7)\end{array}$ & $\begin{array}{l}125 \mathrm{~g} / \mathrm{d} \\
(n=9)\end{array}$ \\
\hline Osmolality (mosmol/kg) & $357 \pm 5$ & $362 \pm 10$ & $348 \pm 5$ & $346 \pm 8$ & $383 \pm 20$ & $385 \pm 26$ \\
\hline $\mathrm{Na}$ (meq/liter) & $10.0 \pm 1$ & $9.9 \pm 2$ & $13.2 \pm 3$ & $19.9 \pm 2^{*}$ & $33 \pm 7$ & $36 \pm 4^{\prime \prime}$ \\
\hline $\mathbf{K}$ (meq/liter) & $16.8 \pm 2$ & $14.5 \pm 1$ & $9.6 \pm 1$ & $8.6 \pm 1^{*}$ & $30 \pm 6$ & $14 \pm 1^{\ddagger}$ \\
\hline $\mathrm{Ca}$ (meq/liter) & $11.3 \pm 3$ & $8.2 \pm 1$ & $4.9 \pm 1$ & $5.7 \pm 0.5^{\prime \prime}$ & $64 \pm 8$ & $24 \pm 2^{*}$ \\
\hline $\mathrm{Mg}$ (meq/liter) & $22.2 \pm 2$ & $11.2 \pm 1$ & $6.4 \pm 1$ & $6.1 \pm 0.4^{*}$ & $15 \pm 3$ & $6.8 \pm 1^{\S}$ \\
\hline $\mathrm{NH}_{4}$ (meq/liter) & $11.8 \pm 1$ & $12.5 \pm 1$ & $8.7 \pm 1$ & $6.6 \pm 0.5^{\ddagger}$ & $4.8 \pm 2$ & $3 \pm 1^{\prime \prime}$ \\
\hline $\mathrm{Cl}$ (meq/liter) & $2.4 \pm 1$ & $8.4 \pm 1$ & $7.2 \pm 1$ & $6.2 \pm 0.5^{\ddagger}$ & $10.2 \pm 4$ & $8.2 \pm 3^{\prime \prime}$ \\
\hline $\mathrm{HCO}_{3}$ (meq/liter) & $2.9 \pm 1$ & $3.4 \pm 1$ & $4.8 \pm 1$ & $7.3 \pm 1.0^{\ddagger}$ & $3.7 \pm 1$ & $1.6 \pm 0.3^{\prime \prime}$ \\
\hline Phosphorus (mmol/liter) & $3.0 \pm 1$ & $4.9 \pm 1$ & $4.5 \pm 1$ & $1.3 \pm 0.2^{\S}$ & $5.1 \pm 1$ & $3.5 \pm 1^{11}$ \\
\hline $\mathrm{pH}$ & $6.6 \pm 0.1$ & $5.9 \pm 0.2$ & $6.3 \pm 0.1$ & $6.4 \pm 0.1^{11}$ & $4.5 \pm 0.1$ & $4.3 \pm 0.1^{11}$ \\
\hline
\end{tabular}

$P$ values, unpaired $t$ test, for the comparison of electrolyte concentrations after ingestion of $252 \mathrm{vs.} 53 \mathrm{~g} / \mathrm{d} P E G$ or $125 \mathrm{vs.} 95 \mathrm{~g} / \mathrm{d}$ lactulose: ${ }^{*} P$ $<0.001 ;{ }^{\ddagger} P<0.01 ;{ }^{\S} P<0.05$. "Not significant.

pared with the lowest PEG dose $(P<0.05)$. Although all of the stools were watery, percent water content averaged $75-80 \%$, only slightly (but significantly, $P<0.01$ ) higher than water content in normal stools. This is due to the high fecal concentration of PEG, a large molecule that makes a considerable contribution to fecal dry weight ( $52 \%$ of fecal dry weight at the lowest PEG dose and $85 \%$ of fecal dry weight at the highest PEG dose). The stool water output increased from 272 to $1,233 \mathrm{~g} / \mathrm{d}$ when $53-252 \mathrm{~g} / \mathrm{d}$ of PEG were ingested.

The concentration of PEG in stool rose only modestly as the dose of PEG was progressively increased, but there was an excellent correlation between stool weight or water output and fecal PEG output ( $r=0.97$ and 0.99 , respectively). Average values for organic acid concentration ranged from 31 to 81 meq/liter, and carbohydrate concentrations averaged $\sim 1 \mathrm{~g} /$ liter.

Average values for electrolyte concentrations are shown in Table II. Osmolality was 60-70 mosmol/kg higher than the normal serum osmolality of $290 \mathrm{mosmol} / \mathrm{kg}$. Sodium, chloride, and bicarbonate concentrations in stool were much lower than their respective concentrations in serum, whereas potassium, magnesium, calcium, and ammonium concentrations were higher than their concentrations in serum. Phosphorus concentrations were similar to that of serum. Average stool pH was between 5.9 and 6.6 .

Table III shows total daily losses of solutes, which were calculated by multiplying supernate concentrations in 24-h samples by stool weight. There were slight but significant increases in fecal losses of ions (except magnesium), organic acids, and fat as stool weight increased due to increased doses of PEG.

Diarrhea induced by lactulose. Table I shows that mean stool weight increased from 254 to $1307 \mathrm{~g} / \mathrm{d}$ as lactulose dose was increased from 45 to $125 \mathrm{~g} / \mathrm{d}$. The average weight of individual bowel movements increased significantly as daily stool weight increased $(P<0.001)$. The percent water content of the

Table III. Total Daily Fecal Output of Solutes Measured in 24-h Stool Collections

\begin{tabular}{|c|c|c|c|c|c|c|c|}
\hline & \multicolumn{4}{|c|}{ PEG } & \multicolumn{3}{|c|}{ Lactulose } \\
\hline & $\begin{array}{c}53 \mathrm{~g} / \mathrm{d} \\
(n=7 \text { or } 9)\end{array}$ & $\begin{array}{c}95 \mathrm{~g} / \mathrm{d} \\
(n=9)\end{array}$ & $\begin{array}{c}190 \mathrm{~g} / \mathrm{d} \\
(n=12)\end{array}$ & $\begin{array}{l}252 \mathrm{~g} / \mathrm{d} \\
(n=9)\end{array}$ & $\begin{array}{l}45 \mathrm{~g} / \mathrm{d} \\
(n=9)\end{array}$ & $\begin{array}{c}95 \mathrm{~g} / \mathrm{d} \\
(n=7 \text { or } 9)\end{array}$ & $\begin{array}{l}125 \mathrm{~g} / \mathrm{d} \\
(n=9)\end{array}$ \\
\hline Stool weight $(g / d)$ & $364 \pm 41$ & $589 \pm 45$ & $1,118 \pm 102$ & $1,539 \pm 77$ & $254 \pm 45$ & $550 \pm 115$ & $1,307 \pm 111$ \\
\hline $\mathrm{Na}(m e q / d)$ & $4 \pm 1$ & $6 \pm 1$ & $14 \pm 2$ & $31 \pm 4^{*}$ & & $21 \pm 5$ & $49 \pm 9 \neq$ \\
\hline $\mathbf{K}(m e q / d)$ & $6 \pm 1$ & $9 \pm 1$ & $11 \pm 1$ & $13 \pm 1^{*}$ & & $16 \pm 3$ & $18 \pm 1^{11}$ \\
\hline $\mathrm{Ca}(m e q / d)$ & $4 \pm 1$ & $5 \pm 1$ & $5 \pm 1$ & $9 \pm 1^{\ddagger}$ & & $39 \pm 8$ & $32 \pm 4^{\| \prime}$ \\
\hline $\mathrm{Mg}(m e q / d)$ & $8 \pm 1$ & $7 \pm 1$ & $8 \pm 1$ & $10 \pm 1^{\| \prime}$ & & $9 \pm 2$ & $9 \pm 2^{11}$ \\
\hline $\mathrm{NH}_{4}(m e q / d)$ & $4 \pm 2$ & $7 \pm 1$ & $10 \pm 1$ & $10 \pm 1^{*}$ & & $3 \pm 1$ & $5 \pm 2^{11}$ \\
\hline $\mathrm{Cl}(m e q / d)$ & $1 \pm 0.4$ & $5 \pm 0.3$ & $8 \pm 1$ & $10 \pm 1^{*}$ & & $6 \pm 3$ & $13 \pm 5^{\prime \prime}$ \\
\hline $\mathrm{HCO}_{3}(m e q / d)$ & $1 \pm 0.3$ & $5 \pm 0.5$ & $5 \pm 0.8$ & $11 \pm 2 *$ & & $2 \pm 0.7$ & $2 \pm 0.4^{\prime \prime}$ \\
\hline Phosphorus $(\mathrm{mmol} / \mathrm{d})$ & $1 \pm 0.3$ & $3 \pm 0.6$ & $5 \pm 1$ & $2 \pm 0.3^{\ddagger}$ & & $4 \pm 0.6$ & $5 \pm 2^{\prime \prime}$ \\
\hline Carbohydrate $(g / d)$ & $0.3 \pm 0.1^{\top}$ & $0.8 \pm 0.1$ & $0.8 \pm 0.1$ & $1.4 \pm 0.7^{\prime \prime}$ & $1.0 \pm 0.4$ & $12 \pm 5^{* * *}$ & $45 \pm 4^{\S}$ \\
\hline Organic acids (meq/d) & $33 \pm 5^{\pi}$ & $36 \pm 4$ & $57 \pm 7$ & $48 \pm 5^{\ddagger}$ & $61 \pm 13$ & $98 \pm 14^{* *}$ & $151 \pm 20^{*}$ \\
\hline Fat $(g / d)$ & $5.0 \pm 1$ & $7.1 \pm 1$ & $10.3 \pm 2$ & $9.7 \pm 1^{\ddagger}$ & $5.1 \pm 1$ & $8.1 \pm 2^{* *}$ & $5.1 \pm 1^{11}$ \\
\hline
\end{tabular}

$P$ values for the comparison of solute output in diarrhea induced by ingestion of $252 \mathrm{vs.} 53 \mathrm{~g} / \mathrm{d}$ of PEG or $125 \mathrm{vs.} 95 \mathrm{~g} / \mathrm{d}$ of lactulose:

* $P<0.001 ;{ }^{\ddagger} P<0.05 ;{ }^{\S} P<0.005$. "Not significant. " $n=7 . \quad{ }^{* *} n=9$. 
stools rose progressively with increasing doses of lactulose, reaching an average high of $90 \%$. Stool water reached a maximum of $1,184 \mathrm{~g} / \mathrm{d}$. Organic acid concentrations decreased $(r$ $=-0.77, P<0.001)$ and fecal carbohydrate concentrations increased $(r=0.75, P<0.001)$ as stool weight increased. Fecal carbohydrate and organic acid concentrations were negatively correlated $(r=-0.83, P<0.001)$. There was no correlation between fecal organic acid concentration and the weight of individual bowel movements.

A supernatant suitable for electrolyte analysis could not be obtained from eight of nine 24-h stool collections when $45 \mathrm{~g} / \mathrm{d}$ of lactulose was ingested and from two of nine stool collections when $95 \mathrm{~g} / \mathrm{d}$ of lactulose was ingested (Table IV). 7 of these 10 samples were mushy and unformed; 3 were formed and of normal consistency. Percent water content in some of the formed samples was as high as in unformed samples; consistency of feces therefore depended not only on water content but presumably also on physical and chemical properties of stool matrix (23). Organic acid concentration in unformed samples obtained during ingestion of $45 \mathrm{~g} / \mathrm{d}$ of lactulose was significantly higher than in formed samples $(267 \pm 21 \mathrm{meq} / \mathrm{liter}$ in unformed samples, $158 \pm 6 \mathrm{meq} /$ liter in formed samples, $P$ $<0.02$ ). Fecal carbohydrate concentration was highly variable; carbohydrate concentration in some of the unformed samples was as high as $10 \mathrm{~g} /$ liter.

Results of electrolyte analysis on 24-h collections obtained during ingestion of the two higher lactulose doses are shown in Table II. Mean stool osmolality was $\sim 90 \mathrm{mosmol} / \mathrm{kg}$ higher than serum osmolality. Mean fecal $\mathrm{pH}$ was $\sim 4.4$. Fecal concentration of sodium and inorganic anions did not change but concentrations of potassium, calcium, and magnesium fell significantly as the dose of lactulose and stool weight increased. As shown in Table III, daily stool collections contained 1, 12, and $45 \mathrm{~g}$ of carbohydrate when the subjects were ingesting 45 , 95 , and $125 \mathrm{~g}$ of lactulose/d. Total daily output of sodium and organic acids also increased significantly with increasing doses of lactulose.

To assess whether measured carbohydrate concentration after $24 \mathrm{~h}$ was influenced by bacterial metabolism during the daily cold storage period, we measured carbohydrate and or- ganic acid concentrations in five samples of diarrhea (induced by $125 \mathrm{~g} / \mathrm{d}$ of lactulose) as soon as possible after defecation (it took 30 min until supernatant was analyzed) and after 1, 24 , and $72 \mathrm{~h}$ of storage in an ice chest. Carbohydrate concentration remained constant at $\sim 25 \mathrm{~g} /$ liter, whereas organic acid concentration increased from 62 to $78.5 \mathrm{meq} / \mathrm{liter}(P$ $<0.05$, paired $t$ test) during cold storage for $72 \mathrm{~h}$. Osmolality increased (from 306 to $346 \mathrm{mosmol} / \mathrm{kg}, P<0.05$ ), whereas $\mathrm{pH}$ decreased (from 5.32 to $4.73, P<0.05$ ) during storage for $72 \mathrm{~h}$. The rise in osmolality could be due to the rising concentration of organic acids, and to conversion of disaccharide (lactulose) to monosaccharides without a change in total concentration of carbohydrate. Both of these proposed mechanisms imply some continued fermentation by fecal flora during storage in the ice chest.

Comparison of PEG- and lactulose-induced diarrhea. The PEG contribution to the osmolality of fecal fluid in PEG-induced diarrhea was $142,197,207$, and $198 \mathrm{mosmol} / \mathrm{kg}$ with $53,95,190$, and $252 \mathrm{~g} / \mathrm{d}$ of PEG. The total PEG osmotic load was 52, 116, 231, and $305 \mathrm{mosmol} / \mathrm{d}$ on the four PEG dose regimens, respectively. A similar calculation is not possible with fermentable solutes; however, the total osmotic load of ingested lactulose, expressed in milliosmoles ingested/day, was 131,278 , and $365 \mathrm{mosmol} / \mathrm{d}$, respectively, on the three lactulose doses. Since lactulose is not absorbed in the small bowel (12), these amounts of lactulose must have reached the cecum.

Fig. 1 shows that increasing osmotic loads of PEG caused a near linear increase in stool water output. Stool water output caused by the two lower doses of lactulose was considerably less than that caused by comparable amounts of PEG. Thus, the dose-response curve (relating solute load and stool water) with lactulose was shifted to the right by $\sim 160 \mathrm{mosm} / \mathrm{d}$. This accounted for a maximal reduction in stool water output of $600 \mathrm{~g} / \mathrm{d}$ in lactulose-induced diarrhea as compared with diarrhea induced by PEG. However, with the largest dose of lactulose the increment in stool water output (increment above water output with the medium dose) was even steeper than the PEG-stool water regression line.

Fig. $2 A$ shows that fecal cation concentrations (sum of sodium, potassium, calcium, and magnesium concentrations)

Table IV. Results in Selected Individual 24-h Stool Collections

\begin{tabular}{|c|c|c|c|c|c|c|}
\hline & Stool weight & Stool frequency & Consistency & Water content & Organic acids & Carbohydrate \\
\hline & $g / d$ & times/d & & $\%$ & meq/liter & g/liter \\
\hline \multirow[t]{9}{*}{ Lactulose $(45 \mathrm{~g} / \mathrm{d})$} & 158 & 2 & Unformed & 76.8 & 234.4 & 2.6 \\
\hline & 139 & 1 & Unformed & 78.4 & 228.6 & 1.8 \\
\hline & 368 & 2 & Unformed & 81.5 & 235.9 & 0.6 \\
\hline & 231 & 1 & Unformed & 75.8 & 346.3 & 10.2 \\
\hline & 369 & 2 & Unformed & 76.7 & 320.9 & 10.4 \\
\hline & $469^{*}$ & 2 & Unformed & 85.0 & 234.0 & 2.1 \\
\hline & 258 & 2 & Formed & 78.3 & 163.3 & 1.0 \\
\hline & 265 & 2 & Formed & 79.2 & 145.7 & 1.6 \\
\hline & 29 & 1 & Formed & 75.1 & 165.7 & 2.2 \\
\hline \multirow[t]{2}{*}{ Lactulose ( $95 \mathrm{~g} / \mathrm{d})$} & 199 & 3 & Unformed & 82.4 & 255.6 & 10.0 \\
\hline & 259 & 4 & Unformed & 81.3 & 243.2 & 3.4 \\
\hline
\end{tabular}

All results from the 45-g lactulose study are presented; for the 95-g lactulose study, two collections from which a supernatant could not be obtained are included. * Supernate was obtained and analyzed in this sample: osmolality $400 \mathrm{mosmol} / \mathrm{kg}, \mathrm{Na} 58 \mathrm{meq} / \mathrm{liter}, \mathrm{K} 53 \mathrm{meq} / \mathrm{liter}, \mathrm{Ca}$ $42 \mathrm{meq} /$ liter, $\mathrm{Mg} 29 \mathrm{meq} / \mathrm{liter}, \mathrm{NH}_{4} 12 \mathrm{meq} / \mathrm{liter}, \mathrm{Cl} 27 \mathrm{meq} / \mathrm{liter}, \mathrm{HCO}_{3} 0.4 \mathrm{meq} / \mathrm{liter}$, phosphorus $7.0 \mathrm{meq} / \mathrm{liter}, \mathrm{pH} 5.4$. 


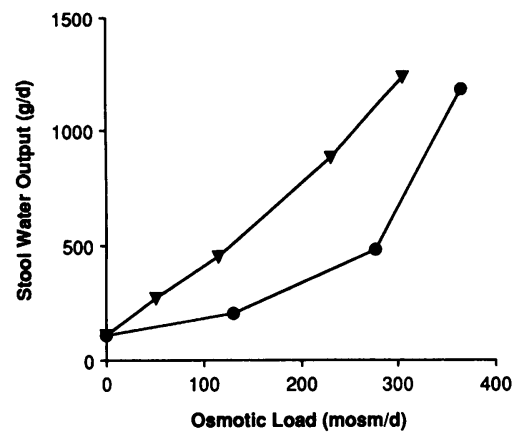

Figure 1. Influence of the osmotic load of PEG (triangles) and lactulose (circles) on daily stool water output.

decreased significantly in PEG- $(P<0.01)$ and lactulose-induced $(P<0.001)$ diarrhea as stool weight increased. At lower stool weights cation concentration in lactulose-induced diarrhea was about three times higher than in PEG-induced diarrhea; at high stool weights cation concentrations in lactuloseinduced diarrhea were only slightly higher than in PEG-induced diarrhea. As shown in Fig. $2 B$, there was a very good correlation between organic acid concentration and fecal cation concentration; organic acid concentration in lactulose-induced diarrhea was significantly higher than in PEG-induced diarrhea $(P<0.001)$. As already pointed out, Fig. $2 B$ shows effects on the sum of all measured inorganic cations. To determine the relative magnitude of accumulation of the individual cations, we calculated the correlation between organic acid output and output of individual cations in PEG- and lactulose-induced diarrhea. Accumulation of cations was in following order: $\mathrm{Na}$ (slope of the regression line $=0.30, r$ $=0.76, P<0.001)>\mathrm{Ca}$ (slope $=0.21, r=0.69, P<0.001$ ) $>\mathrm{K}$ (slope $=0.07, r=0.71, P<0.001)>\mathrm{Mg}$ (slope $=0.02, r$ $=0.29, P<0.05$ ).

Inorganic anion concentrations (sum of chloride, bicarbonate, and phosphorus) in lactulose- and PEG-induced diarrhea were not significantly different and they did not correlate with organic acid concentration (data not shown).

Mean fecal $\mathrm{pH}$ and ammonium concentration in lactulose-induced diarrhea were significantly lower $(P<0.001)$ than in PEG-induced diarrhea.

\section{Discussion}

Increasing osmotic loads of PEG resulted in a near linear increase in stool weight and stool water output. The concentra-
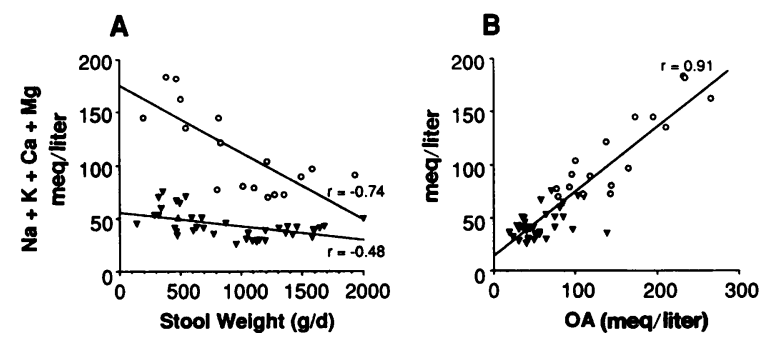

Figure 2. A, Correlation between stool weight and the sum of fecal concentrations of inorganic cations in lactulose- (open circles) and PEG-induced (closed triangles) diarrhea. $B$, Correlation between fecal organic acid $(O A)$ concentration and the sum of fecal concentrations of inorganic cations in lactulose- (open circles) and PEG-induced (closed triangles) diarrhea.

tion of PEG in diarrheal fluid was only modestly higher with the largest dose of PEG than with the smallest dose. Stool water output in osmotic diarrhea induced by PEG therefore did not correlate with fecal PEG concentration in stool (which at the three higher doses of PEG remained relatively constant regardless of the severity of diarrhea), but was well correlated with total fecal PEG output. The contribution of PEG to the osmolality of fecal fluid was $142 \mathrm{mosmol} / \mathrm{kg}$ with the low dose of PEG and between 197 and $207 \mathrm{mosmol} / \mathrm{kg}$ with the three higher doses of PEG. Assuming that fecal osmolality at the time of bowel movement is approximately the same as serum osmolality (see final paragraph of Discussion), this means that in osmotic diarrhea $\sim 50-70 \%$ of fecal osmolality is made up by the osmotic agent that causes the diarrhea, with the remaining $50-30 \%$ made up by other solutes, of either dietary, endogenous, or bacterial origin. We analyzed the fecal fluid for electrolytes, ammonium, carbohydrate, and organic acid concentration, and when these solutes were considered, most or all of the osmolality could be accounted for.

PEG-induced diarrhea was associated with very small enteric losses of sodium, potassium, and chloride. Even when stool water output exceeded $1,200 \mathrm{~g} / \mathrm{d}$, the total daily fecal excretion of these monovalent electrolytes was only a small fraction of normal daily dietary intake. This is a tribute to the efficiency with which the human intestine absorbs these ions, in some cases against steep electrochemical gradients. Perhaps most surprising is the small potassium loss during such severe diarrhea. Because potassium movement in the human intestine is mainly dependent on passive forces (24), we would have expected the large intestinal flow rates created by osmotic diarrhea to have resulted in much larger potassium losses.

Increasingly severe PEG-induced diarrhea was associated with a slight increase in fecal carbohydrate, fat, and organic acid excretion in stool. Presumably this is because of shortened transit time through the small bowel and colon and dilution, causing a reduction in the absorption of fat and carbohydrate in the small intestine and a reduction of organic acid absorption in the colon.

In lactulose-induced diarrhea, daily stool collections contained an average of 1,12 , and $45 \mathrm{~g}$ of carbohydrate when the subjects were ingesting 45,95 , and $125 \mathrm{~g}$ of lactulose/d. The difference in these intake and output values must represent bacterial metabolism, and this could have occurred both in vivo in the colon and ex vivo during cold storage for $1 \mathrm{~d}$ before the specimens were analyzed. However, in separate experiments we showed that fecal carbohydrate concentration did not change significantly during cold storage for up to $72 \mathrm{~h}$; we conclude that the difference between daily lactulose intake and carbohydrate output is due to bacterial metabolism of lactulose within the colonic lumen. We can therefore calculate that 44,83 , and $80 \mathrm{~g}$ of lactulose were metabolized in vivo by colonic bacteria each day when our subjects ingested 45,95 , and $125 \mathrm{~g}$ of lactulose/d. Under these conditions, the capacity of colonic bacteria to metabolize lactulose to noncarbohydrate moieties is $\sim 80 \mathrm{~g} / \mathrm{d}$.

For every gram of carbohydrate metabolized by colonic bacteria, $10.6 \mathrm{meq}$ of organic acids are generated (25). Since 80 $\mathrm{g}$ of carbohydrate was metabolized when $125 \mathrm{~g}$ of lactulose was ingested, $\sim 848$ meq of organic acids were presumably produced within the colonic lumen. Excess organic acid excretion in feces (excretion during lactulose minus excretion during 
comparable PEG-induced diarrhea) was $103 \mathrm{meq} / \mathrm{d}$ with the $125 \mathrm{~g}$ lactulose load. Therefore, the colon must have absorbed $\sim 745 \mathrm{meq} / \mathrm{d}$ of the organic acids derived from lactulose; this represents an absorption of $\sim 192 \mathrm{kcal} / \mathrm{d}(25,26)$. Similar calculations reveal absorption of 113 and $211 \mathrm{kcal} / \mathrm{d}$ with the 45- and 95-g doses of lactulose.

Bacterial metabolism of unabsorbed lactulose theoretically has three effects on stool weight by virtue of its influence on colonic solute load. The first is an increase in solute load because $1 \mathrm{~mol}$ of disaccharide yields $3.7 \mathrm{~mol}$ of organic acids (25). The second is an increase in solute load because the ionized form of unabsorbed organic acids $(\sim 30 \%$ are ionized at $\mathrm{pH} 4.4$ ) obligate retention of inorganic cations (Fig. $2 \mathrm{~B}$ ); these would contribute to the osmotic activity of colonic fluid. The third effect is a decrease in solute load $(10,11)$ due to absorption of organic acids by the colon (27). We examined the net effect of these conflicting influences by comparing stool water output after ingestion of lactulose and PEG. When $\mathbf{4 5} \mathrm{g}$ of lactulose were ingested only $1 \mathrm{~g}$ of carbohydrate was excreted in the stool, and stool water output rose modestly from a control value of 110 to $202 \mathrm{~g} / \mathrm{d}$. By contrast, with a comparable osmotic load of PEG, expected stool water output was $\sim 500 \mathrm{~g} / \mathrm{d}$. The diarrhea was thus markedly attenuated by bacterial metabolism of lactulose and colonic absorption of organic acids. The mild diarrhea that was observed after $45 \mathrm{~g}$ lactulose was probably mainly due to unabsorbed organic acids, since organic acid concentration and output were much higher after $45 \mathrm{~g}$ lactulose than after the lowest dose of PEG; unabsorbed carbohydrates may have also contributed to this diarrhea, but probably not in a major way, since carbohydrate concentration and output were only slightly higher than in low-volume PEG-induced diarrhea (Tables I and III).

As lactulose doses $>45 \mathrm{~g} / \mathrm{d}$ were ingested, fecal carbohydrate excretion rose progressively, and thereby contributed more and more to the osmotic driving force for diarrhea. The increasing output of organic acids with increasing doses of lactulose (Table III) indicates that organic acids (and their accompanying cations, as explained above) are also a major force for osmotic diarrhea when carbohydrate malabsorption is severe. Decreasing organic acid concentration (as stool weight increased due to higher lactulose doses) reflects the presence of osmotically active carbohydrates, which hold water in the colonic lumen and thereby dilute organic acids. Since $\sim 80 \mathrm{~g}$ of lactulose was metabolized after both the 95- and 125-g lactulose doses, one would expect approximately the same amount of organic acid to be produced within the colonic lumen. The fact that organic acid output in stool was higher after the 125-g dose (Table III) suggests that organic acid absorption was reduced with the higher lactulose dose; possible explanations include dilution of the organic acid concentration (for reasons mentioned above) and reduced contact time between luminal contents and colonic mucosa due to more severe diarrhea.

The net result of these various factors is revealed in Fig. 1, where the osmotic loads of PEG and lactulose are plotted against stool water output. The dose response curve for lactulose is shifted to the right by $160 \mathrm{mosmol} / \mathrm{d}$, and diarrhea is markedly attenuated up to a lactulose intake of $278 \mathrm{mosmol} / \mathrm{d}$ $(95 \mathrm{~g} / \mathrm{d})$. Above that dose, the capacity of colonic flora to metabolize lactulose is saturated; unabsorbed carbohydrate retains water in the colonic lumen, and this dilutes organic acids and thereby retards their absorption; the excess unab- sorbed organic acids exert an osmotic force themselves, and they further obligate cations that have additional osmotic activity. Because of these multiple effects, the increment in osmotically active solutes within the colon exceeds the increment in the osmotic load that was ingested (as lactulose dose was increased from 95 to $125 \mathrm{~g} / \mathrm{d}$ ), and the slope of the regression line becomes steeper than with PEG-induced diarrhea. If still larger doses of lactulose were ingested, it is possible that stool water output would be higher after lactulose than after comparable osmotic loads of PEG.

Several remaining points deserve mention. First, stool pH in lactulose-induced diarrhea was significantly lower than in PEG-induced diarrhea. In all likelihood this is due to the production of organic acids by bacterial metabolism. The fall in stool $\mathrm{pH}$ due to organic acid production was mitigated by colonic absorption of organic acids and presumably also by colonic secretion of bicarbonate. Second, ammonium was the only cation that had a lower fecal concentration in lactulosethan in PEG-induced diarrhea. Decreased bacterial production or increased bacterial utilization of ammonium, which have been suggested to be caused by lactulose ingestion (28), therefore must be substantial to overcome the tendency for cations to accumulate in lactulose-induced diarrhea. Third, we found no correlation between organic acid concentration and the weight of individual bowel movements. This argues against the concept that organic acids may cause rapid colonic emptying due to an effect on colonic motility $(29,30)$. Fourth, our results show that carbohydrate malabsorption can be associated with highly variable stools, i.e., formed, mushy, or liquid stools with normal to very high stool weight. One major determinant of stool consistency and weight is the amount of carbohydrate that is malabsorbed, but the substantial variation among individual subjects when a given amount of lactulose was ingested indicates that other factors are also important. Varying capacities of colonic flora to metabolize carbohydrates and varying colonic absorption rates for organic acids are two likely determining influences. Fifth, although $45 \mathrm{~g} / \mathrm{d}$ of lactulose in four divided doses caused only a small increase in average daily stool weight, one would expect that malabsorption of this amount of carbohydrate would be associated with a marked increase in flatus production (31). Finally, although the osmolality of stool samples stored for $24 \mathrm{~h}$ in an ice chest is significantly higher than serum osmolality (see Results for most likely explanations), the osmolality of fecal fluid at the time of defecation is close to that of serum. This is consistent with the accepted view that the intestinal mucosa has no significant capacity to concentrate the luminal contents by virtue of ion or solute transport, and also suggests that solutes generated within the colon by bacterial metabolism are osmotically equilibrated with plasma by virtue of water and solute movement across the colonic mucosa.

\section{Acknowledgments}

The authors wish to thank Diana Santa Ana for technical assistance and Sharon Michael for help in preparing the manuscript.

This work was supported by U. S. Public Health Service grant 5-ROI-DK37172-04 from the National Institute of Arthritis, Metabolism and Digestive Diseases, and a grant from the David Bruton, Jr. trust. Dr. Hammer was supported by an Erwin Schrodinger stipendium (JO251M) from the Austrian Fonds zur Forderung Wissenschaftlicher Forschung. 


\section{References}

1. Flinn, R. B., J. P. Merrill, and W. R. Welzant. 1961. Treatment of the oliguric patient with a new sodium-exchange resin and sorbitol. N. Engl. J. Med. 264:111-115.

2. Conn, H. O., C. M. Leevy, Z. R. Vlahcevic, J. B. Rodgers, W. C. Maddrey, L. Seeff, and L. L. Levy. 1977. Comparison of lactulose and neomycin in the treatment of chronic portal-systemic encephalopathy. Gastroenterology. 72:573-583.

3. Andersson, D. E. H., and A. Nygren. 1978. Four cases of longstanding diarrhoea and colic pains cured by fructose-free diet: a pathogenetic discussion. Acta Med. Scand. 203:87-92.

4. Hickey, C. A., D. H. Calloway, and E. L. Murphy. 1972. Intestinal gas production following ingestion of fruits and fruit juices. Am. J. Dig. Dis. 17:383-388.

5. Gryboski, J. D. 1966. Diarrhea from dietetic candies. N. Engl. J. Med. 275:718.

6. Goldberg, L. D., and N. T. Ditchek. 1978. Chewing gum diarrhea. Am. J. Dig. Dis. 23:568.

7. Charney, E. B., and J. N. Bodurtha. 1981. Intractable diarrhea associated with the use of sorbitol. J. Pediatr. 98:157-158.

8. Davis, G. R., C. A. Santa Ana, S. G. Morawski, and J. S. Fordtran. 1980. Development of a lavage solution associated with minimal water and electrolyte absorption or secretion. Gastroenterology. 78:991-995.

9. Brady, C. E., J. A. DiPalma, S. G. Morawski, C. A. Santa Ana, and J. S. Fordtran. 1986. Urinary excretion of polyethylene glycol 3350 and sulfate after gut lavage with a polyethylene glycol electrolyte lavage solution. Gastroenterology. 90:1914-1918.

10. Saunders, D. R., and H. S. Wiggins. 1981. Conservation of mannitol, lactulose and raffinose by the human colon. Am. J. Physiol. 4:G397-G402.

11. Flourie, B., C. Florent, J. P. Jouany, P. Thivend, F. Etanchaud, and J. C. Rambaud. 1986. Colonic metabolism of wheat starch in healthy humans: effects on fecal outputs and clinical symptoms. Gastroenterology. 90:111-119.

12. Menzies, I. S., M. F. Laker, R. Pounder, J. Bull, P. Heyer, G. Wheeler, and B. Creamer. 1979. Abnormal intestinal permeability to sugars in villous atrophy. Lancet. ii:1107-1109.

13. Florent, C., B. Flourie, A. Leblond, M. Rautureau, J. J. Bernier, and J. C. Rambaud. 1985. Influence of chronic lactulose ingestion on the colonic metabolism of lactulose in man (an in vivo study). J. Clin. Invest. 75:608-613.

14. American Dietetic Association. 1981. Handbook of Clinical Dietetics. Yale University Press, New Haven. I47.

15. Bo-Linn, G. W., C. A. Santa Ana, S. G. Morawski, and J. S. Fordtran. 1982. Starch blockers: their effect on calorie absorption from a high-starch meal. N. Engl. J. Med. 307:1413-1416.

16. Krejs, G. J., J. H. Walsh, S. G. Morawski, and J. S. Fordtran.
1977. Intractable diarrhea: intestinal perfusion studies and plasma VIP concentrations in patients with pancreatic cholera syndrome and surreptitious ingestion of laxatives and diuretics. Am. J. Dig. Dis. 22:280-292.

17. Sheikh, M. S., J. A. Maguire, M. Emmett, C. A. Santa Ana, M. J. Nicar, L. R. Schiller, and J. S. Fordtran. 1989. Reduction of dietary phosphorus absorption by phosphorus binders. A theoretical, in vitro, and in vivo study. J. Clin. Invest. 83:66-73.

18. Schmulen, A. C., M. Lerman, C. Y. C. Pak, J. Zerwekh, S. Morawski, J. S. Fordtran, and P. Vergne-Marini. 1980. Effect of $1,25-(\mathrm{OH})_{2} \mathrm{D}_{3}$ on jejunal absorption of magnesium in patients with chronic renal disease. Am. J. Physiol. 238:G349-G352.

19. Chaney, A. L., and E. P. Marbach. 1962. Modified reagents for determination of urea and ammonia. Clin. Chem. 8:130-132.

20. Collin, D. P., and P. G. McCormick. 1974. Determination of short chain fatty acids in stool ultrafiltrate and urine. Clin. Chem. 20:1173-1180.

21. Ameen, V. Z., and G. K. Powell. 1985. A simple spectrophotometric method for quantitative fecal carbohydrate measurement. Clin. Chim. Acta. 152:3-9.

22. Schiller, L. R., M. Emmett, C. A. Santa Ana, and J. S. Fordtran. 1988. Osmotic effects of polyethylene glycol. Gastroenterology. 94:933-941.

23. Goy, J. A. E., M. A. Eastwood, W. D. Mitchell, J. L. Pritchard, and A. N. Smith. 1976. Fecal characteristics contrasted in the irritable bowel syndrome and diverticular disease. Am. J. Clin. Nutr. 29:14801484.

24. Giller, J. and S. F. Phillips. 1972. Electrolyte absorption and secretion in the human colon. Am. J. Dig. Dis. 17:1003-1011.

25. Miller, T. L., and M. J. Wolin. 1979. Fermentations by saccharolytic intestinal bacteria. Am. J. Clin. Nutr. 32:164-172.

26. Livesey, G., and M. Elia. 1988. Estimation of energy expenditure, net carbohydrate utilization, and net fat oxidation and synthesis by indirect calorimetry: evaluation of errors with special reference to the detailed composition of fuels. Am. J. Clin. Nutr. 47:608-628.

27. Ruppin, H., S. Bar Meir, K. H. Soergel, C. M. Wood, and M. G. Schmitt. 1980. Absorption of short chain fatty acids by the colon. Gastroenterology. 78:1500-1507.

28. Vince, A., M. Killingley, and O. M. Wrong. 1978. Effect of lactulose on ammonia production in a fecal incubation system. Gastroenterology. 74:544-549.

29. Weijers, H. A., and J. H. van de Kamer. 1963. Aetiology and diagnosis of fermentative diarrhoeas. Acta. Paediatr. 52:329-337.

30. Yajima, T. 1985. Contractile effect of short chain fatty acids on the isolated colon of the rat. J. Physiol. (Lond.). 368:667-678.

31. Levitt, M. D., and J. H. Bond. 1989. Intestinal gas. In Gastrointestinal Disease: Pathophysiology, Diagnosis, Management. M. H. Sleisenger, and J. S. Fordtran, editors. W. B. Saunders Company, Philadelphia. 257-263. 